\title{
A Survey of Image Processing Techniques for Emphysema Detection
}

\author{
Siddhartha Sankar Nath \\ JIS college of engineering \\ Kalyani, Nadia
}

\author{
Pranati Rakshit \\ Asst. Prof., CSE Dept. \\ JIS college of engineering \\ Kalyani, Nadia
}

\begin{abstract}
The main reason behind pulmonary emphysema is mainly due to long-term smoking, and medical treatments are quite difficult. In worst cases, the structure of the lung can get damaged irreversibly. In this case, one of the most important parts is to detect the different stages of the diseases. This requires some well-trained radiologists to observe the changes in the CT scans of the patients over a period of time. But there is dearth of well trained radiologists worldwide. Hence, it would of great help if an accurate computer aided detection (CAD) system for emphysema is developed. Emphysema region classification from $\mathrm{CT}$ image is a time consuming process because there exists many sub-regions because of the huge size of CT image. There exists some sub-regions which contain no sign of Emphysema and the classification of these regions is meaningless. In order to speed up the process of classification, an algorithm has been proposed for selecting the Emphysema affected regions which is region of interest. Then only Emphysema affected region is used for classification instead of all of the sub-regions.
\end{abstract}

\section{General Terms}

Computer aided detection (CAD) system.

\section{Keywords}

CAD, CT, Emphysema, region of interest.

\section{INTRODUCTION}

Computed tomography (CT) scans are performed to find out the pathological changes of the tissues present in the body. CT scans generate a massive quantity of images for examining the pathological change of the tissues. Hence, radiologists get exhausted while diagnosing pathological changes by making use of a lot of CT images. Computer-aided detection (CAD) systems have come into use for speedy disease diagnosis and help the radiologists. For detection of lung diseases like emphysema, lung cancer, etc., CAD systems are extensively used nowadays by taking help of biomedical image processing.

In case of Emphysema detection, standard methodology has been adopted for detecting the Emphysema region in the CT image by classifying sub-regions to identify Emphysema or not. This methodology is quite time consuming because there exists a lot of sub-region which needs to be examined. There exists some sub-region which does not have any Emphysema and performing classification of these sub-regions is a waste of time. In order to reduce the classification time of Emphysema region, it is needed to delete some of the subregions that have no Emphysema.

Any sort of pathological change of the tissues can be known from the local texture and brightness differences in the CT images. The color intensity of the lung CT image can help us in Emphysema detection. Brightness in the lung region helps the radiologists to pre-determine Emphysema region. Fig. 1 depicts a CT lung image with emphysema. On close observation of the image, the emphysema affected region looks darker as compared to the normal region as well as its surface is smooth. Emphysema affected regions can be filtered by utilizing the brightness information of lung region.

In this study, a review of all those available techniques is done to find out the best available technique. Each of the techniques has some advantages as well as disadvantages. Based on this study, it can be determined which technique can be applied in which scenario to obtain the optimal result.

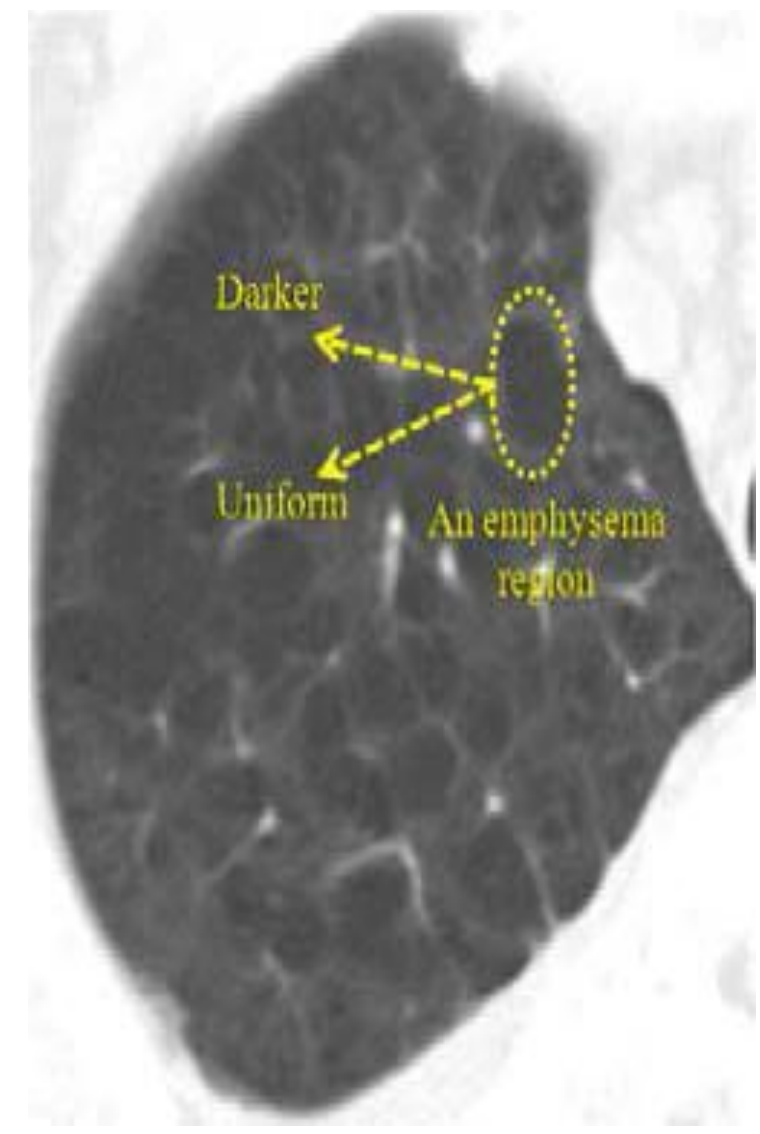

Figure 1: Emphysema affected CT Lung image Picture courtesy: [4]

\section{RELATED WORKS}

Texture descriptors have been used for detecting abnormal regions of lung CT images by Liang et al. [1] and Peng et al. [2] as depicted in Fig. 2. To locate the Emphysema region from the CT image of lung, the contrast of the input image is corrected using gamma correction. Otsu method [3] is used for obtaining the binary image. They used morphology and region growing methodology to remove the noise present in the image and also the lung vessels were deleted to get the lung region without any type of vessels. 

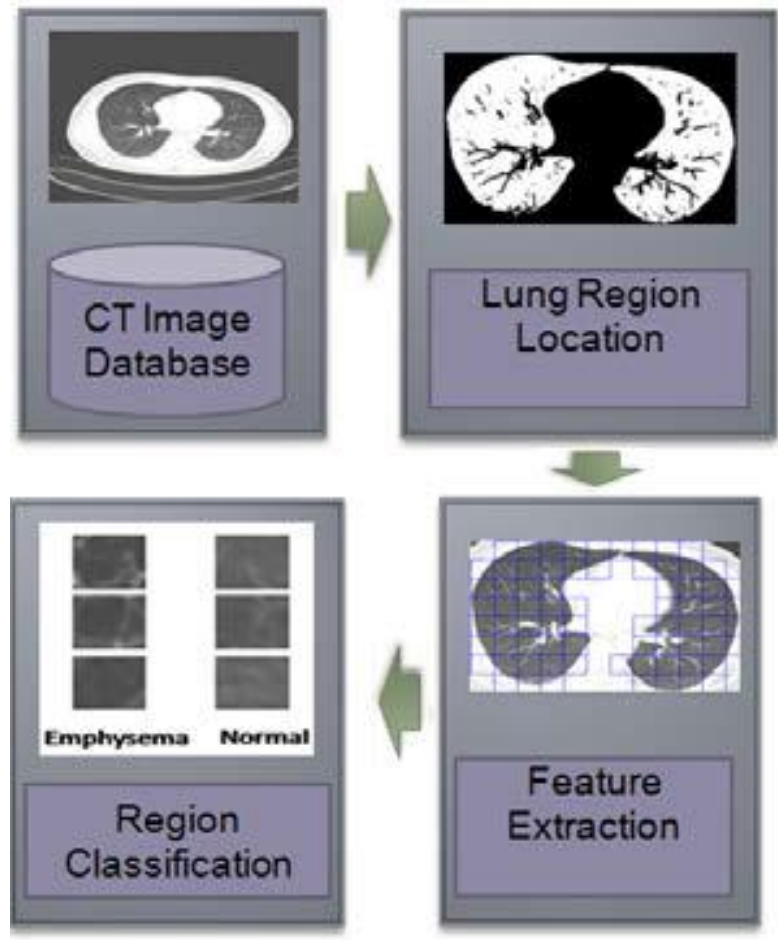

Region Classification

Figure.2: Emphysema Region Classification Scheme Picture courtesy: [4]

KHAIRUL et al. [4] used feature extraction for Emphysema detection. Here, the texture feature of each sub-region is separated from the lung image. The texture feature is extracted using the texture descriptors. This methodology is a time consuming procedure as there exists a lot of sub-region which need to be classified. There is certain sub-region which may not contain any Emphysema at all and the classification of the sub-regions is meaningless and so they removed those regions to speed up the Emphysema region detection process. Finally they used the resultant features are in order to detect whether it contains emphysema or not for region classification process.

EMAM et al. [5] analyzed digital data as obtained from the CT scan for Emphysema detection. This methodology is objective in nature and, hence, not dependent on interpreter bias. There exist two computerized methodologies for detecting emphysema. Low Attenuation Areas (LAA) present in the CT image is considered as a characteristic of emphysema. One approach detects areas of low attenuation depending on a range of density indices or a single density index threshold. So, all the areas whose densities are less than the threshold value (e.g.,910 Hounsfield Units (HU) or falling within a specified range of densities or the lowest fifth percentile of the histogram) are known to be emphysematous. For emphysematous subjects, the lowest fifth percentile of the histograms shows a good correlation with respect to the surface area of walls of distal air spaces per unit lung volume $[6,7]$.Now, the second methodology computes the mean lung density as an important characteristic of emphysema. Both of these techniques have achieved good correlation as compared with some of the pulmonary function tests [7].

For pattern identification in a medical image, Pramod k singh [8] used texture as one of the important characteristics. Gray scale combined with texture information play an important role in HRCT image analysis. Reeves et al.[5] proposed a methodology of texture characterization for JPEG compressed images. They considered the DCT block size in their work as $8 \times 8$. Then segmentation of regions in JPEG images using region growing and unsupervised classification $[9,10]$ is carried out. Their work of emphysema detection is on the similar lines as that of Reaves et al. but it is different on two basic aspects. First of all, they used the standard deviations and statistical mean of the DCT coefficients of a $2 \times 2$ block as compared to some neighboring $2 \times 2$ blocks. For $8 \times 8$ block, JPEG image is transformed to $2 \times 2$ JPEG image. Secondly, a set of concept rules are used for detecting emphysematous patterns; and these rules are utilized for the classification of each 2x2 JPEG image block depending on derived features. The accuracy of detection of emphysema Containing images and patients are nearly more than $96 \%$ if the window size is chosen as $16 \times 16$

In this study, Harvey et. al [11] took the CT image of lung inflation and compared it with the histologic estimates of surface area. In this way they developed prediction equations that allow lung surface to volume ratio and surface area can be predicted from an observation of the CT scan. The result of this study shows that mild emphysema occurs when there is an increase in lung volume as well as reduction in surface to volume ratio. In case of severe emphysema, the surface area and tissue weight decreases. When the CT predicted surface to volume ratio gets correlated with histology, and then both predicted as well as measured surface areas gets correlated with the diffusing capacity. Hence, it can be concluded that the CT analysis can be used for finding out the progression of emphysematous lung destruction in patients. Moreover, they can be used to assess the impact of both surgical and medical treatments for emphysema.

Takeshi et. al [12] adapted an automated detection approach in order to find out the ratio of the pulmonary emphysema regions to the lung volume region. It is used for detecting the rate of lesion development utilizing 3D chest $\mathrm{CT}$ images. Earlier, the degree of the disease was found manually by welltrained radiologists after seeing the hard copy of the CT scan report, as the quantitative analysis of the ratio (abnormal region volume / whole lung volume) was not performed. The emphysema areas were detected by the presence of low attenuation areas (LAA) on CT scans. Their methodology was based on computing the ratio between the region extraction of LAA and volume measurement of the whole lung area except the bronchus regions. They undertook 32 cases (15 normal and 17 abnormal) which had been already diagnosed by radiologists prior to the study. With respect to the results of this approach, the ratio in all normal cases were less than 0.02 , and in abnormal cases, it ranged from 0.01 to 0.26 . All the abnormal cases were classified depending upon the degree of the diseases into three categories (moderate, intermediate, and severe).

Renuka et. al [13] developed a texture-based adaptive multiple feature method (AMFM) for calculating pulmonary parenchyma from computed tomography (CT) images. This methodology utilizes fractal texture as well as multiple statistical features. This AMFM was compared with two previously published methods, such as, lowest fifth percentile of the histogram (HIST) and the mean lung density (MLD). First of all, the ability of these approaches to find subtle differences in ventral-dorsal lung density gradient in the prone normal lung was observed. Second, their different approaches to distinguish between normal and emphysematous lung slices were also compared. Lastly, comparison between normal and emphysematous regions 
were carried out by dividing the lungs in the CT slices into six equal regions, from ventral to dorsal, and then each region is analyzed separately. The results reveal that the AMFM could distinguish the ventral from the dorsal which is about onethird of the normal prone lung with a $89.8 \%$ accuracy, in comparison to an accuracy of $74.6 \%$ with the MLD and $64.4 \%$ accuracy were obtained with the HIST methods. The normal and emphysematous slices were detected with $100.0 \%$ accuracy using the AMFM as compared to an accuracy of 97.4\% and $94.7 \%$ using the HIST and MLD methods, respectively. The regional emphysematous and normal tissues were detected with an accuracy of $89.9 \%, 97.9 \%$ and $99.1 \%$ with the MLD, AMFM and HIST methods, respectively.

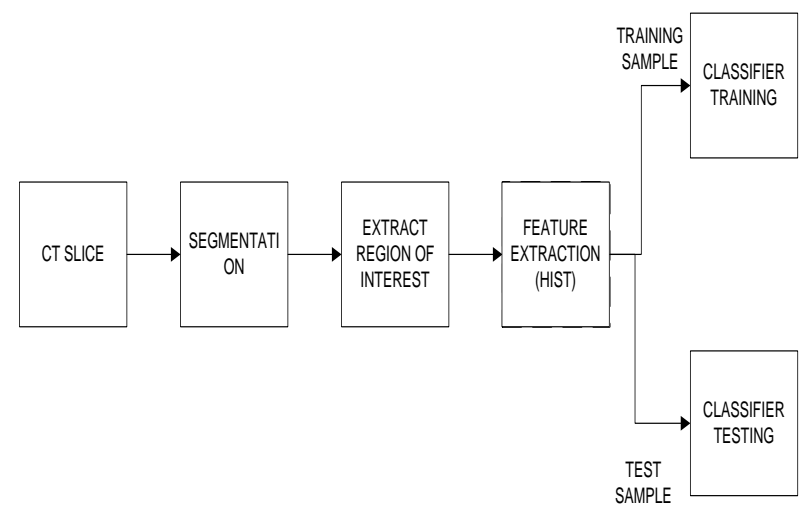

Figure 3: Flowchart showing HIST method Picture courtesy: [13]

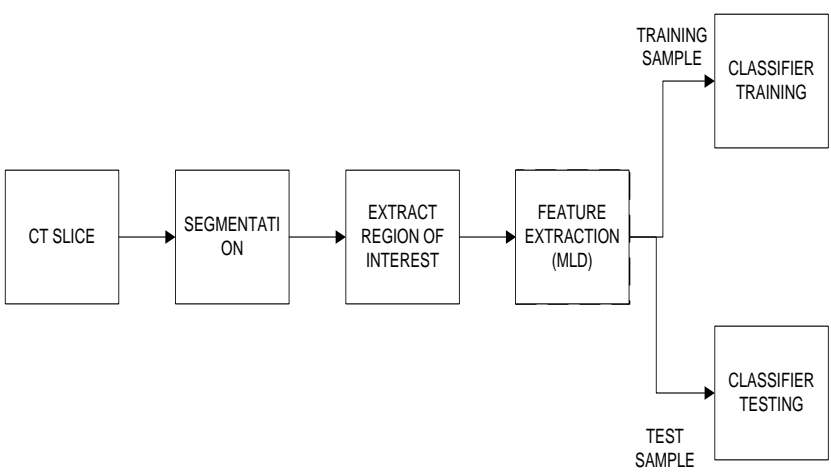

Figure 4: Flowchart showing MLD method Picture courtesy: $[13]$

Mithun et. al [14] developed an automated texture-based system depending on co-training. It has the capability of achieving multiple levels of emphysema extraction in highresolution computed tomography (HRCT) images. Co-training is a semi-supervised approach which is used to improve the performance of classifiers that are trained with very few labeled examples. It utilizes a vast pool of unseen example scenarios over two disjoint feature sets known as views. There is also a scope which allows examples labeled by experts can be incorporated within the system in an incremental manner. The results obtained in this study were also compared with "density mask", which is a standard approach utilized for emphysema detection in the field of medical image analysis and other computerized techniques. This new approach can be used to classify diffuse regions of emphysema starting from a bullous setting. The classifiers are built at different iterations which show an interesting correlation in between different levels of emphysema, which deserves more research. The methodologies used in this paper automate the recognition process. They also help radiologists in the emphysema detection by providing accurate severity calculation from each HRCT scan. This can be obtained by minimum anatomical knowledge. For automated emphysema detection in lung images, a common methodology known as "density mask" is applied to perform thresholding of the image. Moreover, a fixed threshold results in unsatisfactory results as and when the degree of emphysema is low. In this study, we are estimating the degree of emphysema which has not been previously addressed. There are certain computerized techniques for classifying emphysema by using texture and machine learning approaches with a reasonable accuracy percentage. In case of a supervised learning framework, the system is provided with examples which belong to more than one class. All the examples are marked with respect to their membership in any one of the classes. Machine learning systems utilize a general description for the classes from these examples. In case of HRCT setting, labeling is a very time consuming as well as expensive process since it requires expert effort. Hence, it is much advantageous for the unlabelled data as much as possible.

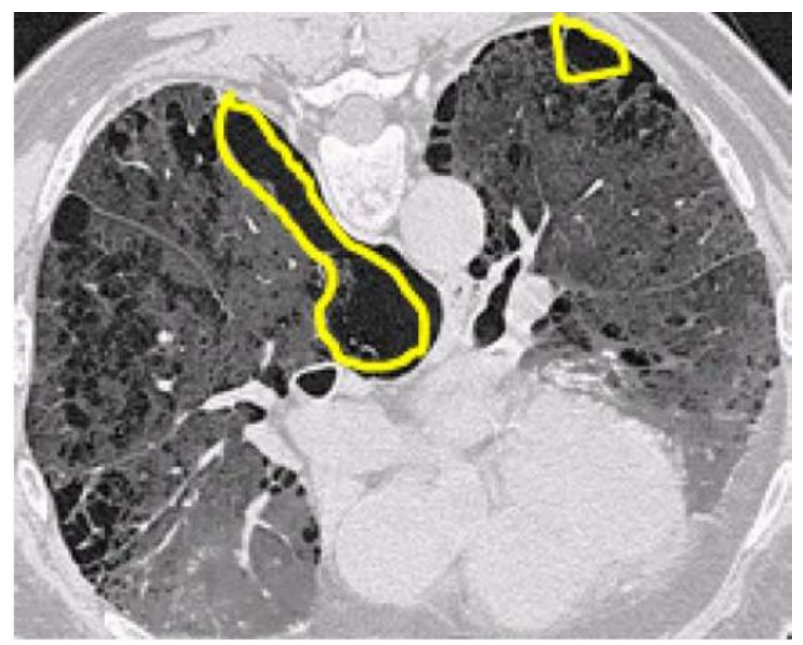

Figure 5: A HRCT scan image showing emphysema. The regions outlined denote emphysema. Picture Courtesy: [14]

Emphysema is a lung disease which can be recognized by its alveolar wall destruction property, which results in the increase of gas exchange spaces without any type of fibrosis. Emphysema is a chronic obstructive pulmonary disease (COPD), resulting in a $3.5 \%$ of total deaths worldwide. A technique known as Alveolar regeneration is working on the animal models and has the potential for clinical treatment if emphysema is detected in an early-stage. However, current methodologies for detection of initial stage emphysema are not sensitive at all. In this study, Josette et. al [15] modeled early-stage human emphysema is in the elastase-treated animals. Here, an in vivo imaging methodology is used for distinguishing emphysematous and normal rat lungs by calculating the apparent diffusion coefficient (ADC) of hyperpolarized $3 \mathrm{He}$ by utilizing the magnetic resonance imaging technique. This study reveals that the ADC is quite larger in case of elastase-treated rats, which indicates an alveolar expansion.

In this study, Lauge et. al [16] aimed at improving the quantitative measures for computed tomography (CT) images of the emphysema affected lungs. In the earlier adopted standard methods, such as the relative area of emphysema (RA), depends upon a single intensity threshold on individual pixels, thus overlooking any type of interrelations that exists 
in between the pixels. Here, texture analysis plays an important role as it takes into account the local structure around the pixels. This study represents a texture based classification system for emphysema quantification in CT images. The degree of emphysema severity can be found out by fusing the pixel posterior probabilities output by a classifier. Here, local binary patterns (LBP) are utilized as the texture features. LBP and intensity histograms are combined for characterizing the regions of interest (ROIs). Then, classification is performed using a nearest neighbor classifier with a histogram having dissimilarity measure as the distance.
The study achieved $95.2 \%$ classification accuracy. The test was carried out on a set of 168 manually annotated ROIs, which consists of the three classes: centrilobular emphysema, paraseptal emphysema and normal tissue. The measurement of emphysema severity was in good arrangement with a pulmonary function test (PFT) which achieves correlation coefficients in 39 subjects. The results obtained in this study were compared to RA as well as to a Gaussian filter bank. The texture-based measures correlated much well with PFT as compared to RA.

Table 1. Review table stated year wise

\begin{tabular}{|c|c|c|c|c|}
\hline $\begin{array}{l}\text { Sl } \\
\text { no. }\end{array}$ & Author & Paper title & Year & Remarks \\
\hline 1 & $\begin{array}{l}\text { Muzzami } \\
\text { l et al. }\end{array}$ & $\begin{array}{c}\text { Accelerating } \\
\text { Emphysema diagnosis } \\
\text { on lung CT images } \\
\text { using Emphysema pre- } \\
\text { detection method [4] }\end{array}$ & 2013 & $\begin{array}{l}\text { Used feature extraction for Emphysema detection. Here, the } \\
\text { texture feature of each sub-region is separated from the lung } \\
\text { image. The texture feature is extracted using the texture } \\
\text { descriptors. This methodology is a time consuming procedure as } \\
\text { there exists a lot of sub-region which need to be classified. There } \\
\text { is certain sub-region which may not contain any Emphysema at all } \\
\text { and the classification of the sub-regions is meaningless and so they } \\
\text { removed those regions to speed up the Emphysema region } \\
\text { detection process. Finally they used the resultant features are in } \\
\text { order to detect whether it contains emphysema or not for region } \\
\text { classification process. }\end{array}$ \\
\hline 2 & $\begin{array}{l}\text { EMAM } \\
\text { et al. }\end{array}$ & $\begin{array}{l}\text { Characterization of } \\
\text { Lung's Emphysema } \\
\text { Distribution: Numerical } \\
\text { Assessment of Disease } \\
\text { Development [5] }\end{array}$ & 2010 & $\begin{array}{l}\text { Analyzed digital data as obtained from the CT scan for } \\
\text { Emphysema detection. This methodology is objective in nature } \\
\text { and, hence, not dependent on interpreter bias. There exist two } \\
\text { computerized methodologies for detecting emphysema. Low } \\
\text { Attenuation Areas (LAA) present in the CT image is considered as } \\
\text { a characteristic of emphysema. One approach detects areas of low } \\
\text { attenuation depending on a range of density indices or a single } \\
\text { density index threshold. So, all the areas whose densities are less } \\
\text { than the threshold value (e.g., } 910 \text { Hounsfield Units (HU) or } \\
\text { falling within a specified range of densities or the lowest fifth } \\
\text { percentile of the histogram) are known to be emphysematous. For } \\
\text { emphysematous subjects, the lowest fifth percentile of the } \\
\text { histograms shows a good correlation with respect to the surface } \\
\text { area of walls of distal air spaces per unit lung volume }\end{array}$ \\
\hline 3 & $\begin{array}{l}\text { Sørensen } \\
\text { et al. }\end{array}$ & $\begin{array}{l}\text { Quantitative Analysis of } \\
\text { Pulmonary } \\
\text { EmphysemaUsing Local } \\
\text { Binary Patterns [16] }\end{array}$ & 2010 & $\begin{array}{l}\text { Proposed a method aimed at improving the quantitative measures } \\
\text { for computed tomography (CT) images of the emphysema affected } \\
\text { lungs. In the earlier adopted standard methods, such as the relative } \\
\text { area of emphysema (RA), depends upon a single intensity } \\
\text { threshold on individual pixels, thus overlooking any type of } \\
\text { interrelations that exists in between the pixels. Here, texture } \\
\text { analysis plays an important role as it takes into account the local } \\
\text { structure around the pixels. This study represents a texture based } \\
\text { classification system for emphysema quantification in CT images. } \\
\text { The degree of emphysema severity can be found out by fusing the } \\
\text { pixel posterior probabilities output by a classifier. Here, local } \\
\text { binary patterns (LBP) are utilized as the texture features. LBP and } \\
\text { intensity histograms are combined for characterizing the regions of } \\
\text { interest (ROIs). Then, classification is performed using a nearest } \\
\text { neighbor classifier with a histogram having dissimilarity measure } \\
\text { as the distance. The study achieved } 95.2 \% \text { classification accuracy. } \\
\text { The test was carried out on a set of } 168 \text { manually annotated ROIs, } \\
\text { which consists of the three classes: centrilobular emphysema, } \\
\text { paraseptal emphysema and normal tissue. The measurement of } \\
\text { emphysema severity was in good arrangement with a pulmonary } \\
\text { function test (PFT) which achieves correlation coefficients in } 39 \\
\text { subjects. The results obtained in this study were compared to RA } \\
\text { as well as to a Gaussian filter bank. The texture-based measures }\end{array}$ \\
\hline
\end{tabular}




\begin{tabular}{|c|c|c|c|c|}
\hline & & & & correlated much well with PFT as compared to RA. \\
\hline 4 & $\begin{array}{l}\text { Peng et } \\
\text { al. }\end{array}$ & $\begin{array}{c}\text { Speeded Up Feature } \\
\text { Extraction for CT image } \\
\text { Based on Integral Image } \\
\text { Technique [2] }\end{array}$ & 2009 & $\begin{array}{l}\text { Proposed a method to locate the Emphysema region from the CT } \\
\text { image of lung, the contrast of the input image is corrected using } \\
\text { gamma correction }\end{array}$ \\
\hline 5 & $\begin{array}{l}\text { Mohanali } \\
\text { n et al. }\end{array}$ & $\begin{array}{l}\text { Tsallis Entropy based } \\
\text { Microcalcification } \\
\text { Segmentation [6] } \\
\text { 3. }\end{array}$ & 2009 & $\begin{array}{l}\text { Introduced a methodology which computes the mean lung density } \\
\text { as an important characteristic of emphysema. Both of these } \\
\text { techniques have achieved good correlation as compared with some } \\
\text { of the pulmonary function tests }\end{array}$ \\
\hline 6 & $\begin{array}{l}\text { Liang et } \\
\text { al. }\end{array}$ & $\begin{array}{l}\text { A Neural Network based } \\
\text { Computer-Aided } \\
\text { Diagnosis of } \\
\text { Emphysema using CT } \\
\text { Lung Images[1] }\end{array}$ & 2007 & $\begin{array}{l}\text { Introduce a method in which texture descriptors have been used } \\
\text { for detecting abnormal regions of lung CT images }\end{array}$ \\
\hline 7 & $\begin{array}{l}\text { Prasad et } \\
\text { al. }\end{array}$ & $\begin{array}{l}\text { Multi-level classification } \\
\text { of emphysema in HRCT } \\
\text { lung images[14] }\end{array}$ & 2007 & $\begin{array}{l}\text { Developed an automated texture-based system depending on co- } \\
\text { training. It has the capability of achieving multiple levels of } \\
\text { emphysema extraction in high-resolution computed tomography } \\
\text { (HRCT) images. Co-training is a semi-supervised approach which } \\
\text { is used to improve the performance of classifiers that are trained } \\
\text { with very few labeled examples. It utilizes a vast pool of unseen } \\
\text { example scenarios over two disjoint feature sets known as views. } \\
\text { There is also a scope which allows examples labeled by experts } \\
\text { can be incorporated within the system in an incremental manner. }\end{array}$ \\
\hline 8 & $\begin{array}{l}\text { Singh et } \\
\text { al. }\end{array}$ & $\begin{array}{l}\text { Emphysema detection in } \\
\text { JPEG compressed } \\
\text { HRCT lung Images[8] }\end{array}$ & 2005 & $\begin{array}{l}\text { Used texture as one of the important characteristics. Gray scale } \\
\text { combined with texture information play an important role in } \\
\text { HRCT image analysis }\end{array}$ \\
\hline 9 & $\begin{array}{l}\text { Singh et } \\
\text { al. }\end{array}$ & $\begin{array}{l}\text { Segmentation of JPEG } \\
\text { Compressed Medical } \\
\text { Images[10] }\end{array}$ & 2004 & $\begin{array}{l}\text { Proposed a method which considered the DCT block size in their } \\
\text { work as } 8 \times 8 \text {. Then segmentation of regions in JPEG images using } \\
\text { region growing and unsupervised classificatio is carried out. Their } \\
\text { work of emphysema detection is on the similar lines as that of } \\
\text { Reaves et al. but it is different on two basic aspects. First of all, } \\
\text { they used the standard deviations and statistical mean of the DCT } \\
\text { coefficients of a } 2 \times 2 \text { block as compared to some neighboring } 2 \times 2 \\
\text { blocks. For } 8 \times 8 \text { block, JPEG image is transformed to } 2 \times 2 \text { JPEG } \\
\text { image. Secondly, a set of concept rules are used for detecting } \\
\text { emphysematous patterns; and these rules are utilized for the } \\
\text { classification of each } 2 \times 2 \text { JPEG image block depending on derived } \\
\text { features. The accuracy of detection of emphysema Containing } \\
\text { images and patients are nearly more than } 96 \% \text { if the window size } \\
\text { is chosen as } 16 \times 16 \text {. }\end{array}$ \\
\hline 10 & $\begin{array}{l}\text { Hara et } \\
\text { al. }\end{array}$ & $\begin{array}{l}\text { Automated Detection } \\
\text { System for Pulmonary } \\
\text { Emphysema on3D Chest } \\
\text { Images[12] }\end{array}$ & 2004 & $\begin{array}{l}\text { Adapted an automated detection approach in order to find out the } \\
\text { ratio of the pulmonary emphysema regions to the lung volume } \\
\text { region. It is used for detecting the rate of lesion development } \\
\text { utilizing 3D chest CT images. Earlier, the degree of the disease } \\
\text { was found manually by well-trained radiologists after seeing the } \\
\text { hard copy of the CT scan report, as the quantitative analysis of the } \\
\text { ratio (abnormal region volume / whole lung volume) was not } \\
\text { performed. The emphysema areas were detected by the presence of } \\
\text { low attenuation areas (LAA) on CT scans. Their methodology was } \\
\text { based on computing the ratio between the region extraction of } \\
\text { LAA and volume measurement of the whole lung area except the } \\
\text { bronchus regions. They undertook } 32 \text { cases ( } 15 \text { normal and } 17 \\
\text { abnormal) which had been already diagnosed by radiologists prior } \\
\text { to the study. With respect to the results of this approach, the ratio } \\
\text { in all normal cases were less than } 0.02 \text {, and in abnormal cases, it } \\
\text { ranged from } 0.01 \text { to } 0.26 \text {. All the abnormal cases were classified } \\
\text { depending upon the degree of the diseases into three categories } \\
\text { (moderate, intermediate, and severe). }\end{array}$ \\
\hline
\end{tabular}




\begin{tabular}{|c|c|c|c|c|}
\hline 11 & $\begin{array}{l}\text { Feng et } \\
\text { al. }\end{array}$ & $\begin{array}{l}\text { Image Segmentation in } \\
\text { CompressedDomain[9] }\end{array}$ & 2003 & $\begin{array}{l}\text { Introduced a method to detect emphysema. It is different on two } \\
\text { basic aspects. First of all, they used the standard deviations and } \\
\text { statistical mean of the DCT coefficients of a } 2 \times 2 \text { block as } \\
\text { compared to some neighboring } 2 \times 2 \text { blocks. For } 8 \times 8 \text { block, JPEG } \\
\text { image is transformed to } 2 \times 2 \text { JPEG image. Secondly, a set of } \\
\text { concept rules are used for detecting emphysematous patterns; and } \\
\text { these rules are utilized for the classification of each } 2 \times 2 \text { JPEG } \\
\text { image block depending on derived features. The accuracy of } \\
\text { detection of emphysema Containing images and patients are nearly } \\
\text { more than } 96 \% \text { if the window size is chosen as } 16 \times 16 \text {. }\end{array}$ \\
\hline 12 & $\begin{array}{l}\text { Coxson et } \\
\text { al. }\end{array}$ & $\begin{array}{l}\text { A Quantification of the } \\
\text { Lung Surface Area in } \\
\text { Emphysema Using } \\
\text { Computed } \\
\text { Tomography[11] }\end{array}$ & 1999 & $\begin{array}{l}\text { Proposed a method which took the CT image of lung inflation and } \\
\text { compared it with the histologic estimates of surface area. In this } \\
\text { way they developed prediction equations that allow lung surface to } \\
\text { volume ratio and surface area can be predicted from an } \\
\text { observation of the CT scan. The result of this study shows that } \\
\text { mild emphysema occurs when there is an increase in lung volume } \\
\text { as well as reduction in surface to volume ratio. In case of severe } \\
\text { emphysema, the surface area and tissue weight decreases. When } \\
\text { the CT predicted surface to volume ratio gets correlated with } \\
\text { histology, and then both predicted as well as measured surface } \\
\text { areas gets correlated with the diffusing capacity. Hence, it can be } \\
\text { concluded that the CT analysis can be used for finding out the } \\
\text { progression of emphysematous lung destruction in patients. } \\
\text { Moreover, they can be used to assess the impact of both surgical } \\
\text { and medical treatments for emphysema. }\end{array}$ \\
\hline 13 & $\begin{array}{l}\text { Uppaluri } \\
\text { et al. }\end{array}$ & $\begin{array}{l}\text { Quantification of } \\
\text { Pulmonary Emphysema } \\
\text { from Lung Computed } \\
\text { Tomography Images[13] }\end{array}$ & 1997 & $\begin{array}{l}\text { Developed a texture-based adaptive multiple feature method } \\
\text { (AMFM) for calculating pulmonary parenchyma from computed } \\
\text { tomography (CT) images. This methodology utilizes fractal texture } \\
\text { as well as multiple statistical features. This AMFM was compared } \\
\text { with two previously published methods, such as, lowest fifth } \\
\text { percentile of the histogram (HIST) and the mean lung density } \\
\text { (MLD). First of all, the ability of these approaches to find subtle } \\
\text { differences in ventral-dorsal lung density gradient in the prone } \\
\text { normal lung was observed. Second, their different approaches to } \\
\text { distinguish between normal and emphysematous lung slices were } \\
\text { also compared. Lastly, comparison between normal and } \\
\text { emphysematous regions were carried out by dividing the lungs in } \\
\text { the CT slices into six equal regions, from ventral to dorsal, and } \\
\text { then each region is analyzed separately. The results reveal that the } \\
\text { AMFM could distinguish the ventral from the dorsal which is } \\
\text { about one-third of the normal prone lung with a } 89.8 \% \text { accuracy, } \\
\text { in comparison to an accuracy of } 74.6 \% \text { with the MLD and } 64.4 \% \\
\text { accuracy were obtained with the HIST methods. The normal and } \\
\text { emphysematous slices were detected with } 100.0 \% \text { accuracy using } \\
\text { the AMFM as compared to an accuracy of } 97.4 \% \text { and } 94.7 \% \text { using } \\
\text { the HIST and MLD methods, respectively. The regional } \\
\text { emphysematous and normal tissues were detected with an } \\
\text { accuracy of } 89.9 \% \text {, } 97.9 \% \text { and } 99.1 \% \text { with the MLD, AMFM and } \\
\text { HIST methods, respectively. }\end{array}$ \\
\hline 14 & Otsu et al & $\begin{array}{l}\text { A Threshold Selection } \\
\text { Method from Gray- } \\
\text { Level Histogram[3] }\end{array}$ & 1979 & $\begin{array}{l}\text { Introduce a technique used for obtaining the binary image. They } \\
\text { used morphology and region growing methodology to remove the } \\
\text { noise present in the image and also the lung vessels were deleted to } \\
\text { get the lung region without any type of vessels. }\end{array}$ \\
\hline 15 & $\begin{array}{l}\text { American } \\
\text { Thoracic } \\
\text { Society. }\end{array}$ & $\begin{array}{l}\text { Chronic bronchitis, } \\
\text { asthma, and pulmonary } \\
\text { emphysema: a statement } \\
\text { by the committee on } \\
\text { diagnostic standards for } \\
\text { nontuberculous[7] }\end{array}$ & 1962 & $\begin{array}{l}\text { Develop a methodology computes the mean lung density as an } \\
\text { important characteristic of emphysema. Both of these techniques } \\
\text { have achieved good correlation as compared with some of the } \\
\text { pulmonary function tests }\end{array}$ \\
\hline
\end{tabular}




\section{CONCLUSION}

In this review paper, many works related to automated emphysema detection were studied. Different techniques used different approaches for emphysema detection. Among all of the techniques studied above, the text feature based adaptive multiple feature method achieved the highest accuracy.

Emphysema is one of the vital factors contributing to majority of lung diseases worldwide. So, there is a need for development of some inexpensive automated technique for accurate detection of different stages of emphysema. These techniques will be of great help in less developed countries where there is an acute shortage of radiologists. There have been several works done earlier in this field. In future, there arises a need to develop more accurate, robust as well as affordable automated techniques for emphysema detection so that the benefits are passed on the poorest of poor people. The current available techniques don't tell us about the degree of severity of the disease. It would be better if a proper automated classification system is developed in future which can analyze a patient's current state into mild, intermediate or severe.

Once emphysema is correctly diagnosed so proper medicine or surgery can be done in a timely manner to avoid death.

\section{ACKNOWLEDGMENTS}

My sincere thanks to prof. Pranati Rakshit who has guided me in writing in this paper.

\section{REFERENCES}

[1] T. K. Liang, T. Tanaka, H. Nakamura and A. Ishizaka, "A Neural Network based Computer-Aided Diagnosis of Emphysema using CT Lung Images", SICE Annual Conference, pp 703-709, 2007

[2] Shao-Hu Peng, Hyun-Soo Kim and Deok-Hwan Kim, "Speeded Up Feature Extraction for CT image Based on Integral Image Technique”, IFMIA, pp. 319-324, 2009.

[3] N. Otsu, "A Threshold Selection Method from GrayLevel Histogram",. IEEE Trans.on Sys. Man Cybern. vol. SMC-9, No.1, pp. 62-66, 1979

[4] Khairul Muzzamil Bin Saipullah, Deok-Hwan Kim, Nurul Atiqah Ismail, "Accelerating Emphysema diagnosis on lung CT images using Emphysema predetection method" Journal of Theoretical and Applied Information Technology, Vol. 47 No.1,2013

[5] M. EMAM, J-F RENAUD de la Faverie, N. GHARBI, M.I. El-GOHARY, "Characterization of Lung's Emphysema Distribution: Numerical Assessment of Disease Development" IEEE Xplore, 2010
[6] Mohanalin, Prem Kumar Kalra, Nirmal Kumar. "Tsallis Entropy based Microcalcification Segmentation". ICGST-GVIP Journal, ISSN 1687-398X, Volume (9), Issue (I), February 2009.

[7] American Thoracic Society. 1962. Chronic bronchitis, asthma, and pulmonary emphysema: a statement by the committee on diagnostic standards for nontuberculous respiratory diseases. Am. Rev. Respir. Dis.85:762-768.

[8] Pramod K. Singh, "Emphysema detection in JPEG compressed HRCT lung Images" IEEE Xplore, 2005

[9] G. Feng, and J. Jiang. "Image Segmentation in CompressedDomain". Journal of Electronic Imaging,12(3):390-397, 2003.

[10] P.K. Singh. "Segmentation of JPEG Compressed Medical Images". Proc. Int. Conf. Image Process, 2004.

[11] HARVEY O. COXSON, ROBERT M. ROGERS, KENNETH P. WHITTALL, YULIA D'YACHKOVA,PETER D. PARÉ, FRANK C. SCIURBA, and JAMES C. HOGG, "A Quantification of the Lung Surface Area in Emphysema Using Computed Tomography" Am J Respir Crit Care Med Vol 159. pp 851-856, 1999

[12] Takeshi Hara, Akira Yamamoto, Xiangrong Zhou, Shingo Iwano, Shigeki Itoh, Hiroshi Fujita, and Takeo Ishigaki, "Automated Detection System for Pulmonary Emphysema on3D Chest Images" Proceedings of SPIE Vol. 5370,Medical Imaging 2004

[13] RENUKA UPPALURI, THEOPHANO MITSA, MILAN SONKA, ERIC A. HOFFMAN and GEOFFREY MCLENNAN, "Quantification of Pulmonary Emphysema from Lung Computed Tomography Images" AM J RESPIR CRIT CARE MED 1997;156:248-254.

[14] Mithun Prasad, Arcot Sowmya, Peter Wilson "Multilevel classification of emphysema in HRCT lung images" Springer-Verlag London Limited 2007

[15] X. Josette Chen, Laurence W. Hedlund, Harald E. Mo* ller, Mark S. Chawla, Robert R. Maronpot, and G. Allan Johnson, "Detection of emphysema in rat lungs by using magnetic resonance measurements of $3 \mathrm{He}$ diffusion"PNAS vol. 97 no. 21

[16] Lauge Sørensen, Saher B. Shaker, and Marleen de Bruijne, "Quantitative Analysis of Pulmonary EmphysemaUsing Local Binary Patterns", IEEE TRANSACTIONS ON MEDICAL IMAGING, VOL. 29, NO. 2, FEBRUARY 2010 